\title{
Severe ocular hypertension secondary to systemic corticosteroid treatment in a child with nephrotic syndrome
}

This article was published in the following Dove Press journal:

Clinical Ophthalmology

15 October 2012

Number of times this article has been viewed

\author{
Pedro Nuno Brito' \\ Sérgio Estrela Silva' \\ José Silva Cotta' \\ Fernando Falcão-Reis ${ }^{1,2}$ \\ 'Ophthalmology Department, Hospital \\ S João, Porto, Portugal; ${ }^{2}$ Faculty of \\ Medicine of Porto, University of \\ Porto, Porto, Portugal
}

Purpose: To report a case of severe, acute ocular hypertension in a 6-year-old child, 7 days after initiating treatment with oral prednisolone, due to nephrotic syndrome.

Methods: A 6-year-old female Caucasian child was diagnosed with nephrotic syndrome and treated with oral prednisolone $(60 \mathrm{mg} /$ day). Seven days later the child initiated complaints of headache, vomiting, ocular pain, and photophobia. Ophthalmologic examination revealed a severely increased intraocular pressure (IOP) of $52 \mathrm{mmHg}$ in the right eye and $56 \mathrm{mmHg}$ in the left eye. Anterior segment morphology was evaluated with ultrasound biomicroscopy. Optic disc status was evaluated by disc photography, kinetic perimetry, and optical coherence tomography.

Results: Treatment was initiated with latanoprost, brimonidine, and the fixed association of timolol and dorzolamide. At each follow-up examination, progressively better control of IOP was obtained. Simultaneous with corticosteroid dosage decrease we were able to reduce antiglaucomatous medication while maintaining IOP under control. Ultrasound biomicroscopy revealed an open angle with normal anterior segment echographic findings. Perimetric evaluation revealed normal visual fields in both eyes. Four months after presentation, steroid treatment had been completed and IOP was $10 \mathrm{mmHg}$ in both eyes without any antiglaucomatous medication. Optical coherence tomography revealed normal retinal nerve fiber layer thickness in all peripapillary sectors.

Conclusions: Systemic steroid treatment can cause a severe, acute increase in IOP in children. Children undergoing steroid treatment should have routine ophthalmologic examinations during treatment duration. Prompt antiglaucomatous treatment prevents retinal nerve fiber layer damage and visual acuity loss.

Keywords: glaucoma, children, corticosteroid, nephrotic

\section{Introduction}

The fact that corticosteroids can increase intraocular pressure (IOP) was first described in 1950 by McLean, ${ }^{1}$ and it is now a well-known dose-dependent phenomenon. Other variables influencing the magnitude of IOP response include steroid potency, route of administration, and also the inherent corticosteroid sensitivity of the patient. ${ }^{2}$ Becker ${ }^{3}$ reported that $4 \%-6 \%$ percent of the population were high responders, developing an IOP increase $>15 \mathrm{mmHg}$ and $>31 \mathrm{mmHg}$ after daily corticosteroid use for 4-6 weeks.

Such hypertensive response has been reported to occur with a lower incidence in children, ${ }^{4}$ but a few studies ${ }^{5,6}$ indicate that the magnitude of IOP increase seems to be higher than in adults, especially in children under 6 years of age. ${ }^{7}$ Even though the 
hypertensive response can occur with any form of steroid administration, the time frame for an IOP increase is variable, ranging from a few weeks with topic corticosteroids ${ }^{8,9}$ to a few years with systemic administration. ${ }^{10}$ The purpose of this report is to describe a clear association between systemic steroid dosage and subsequent rapid IOP response in a child with nephrotic syndrome and no family history of glaucoma or other significant ophthalmologic condition.

\section{Case report}

A 6-year-old female Caucasian child was diagnosed with nephrotic syndrome and treated with oral prednisolone $60 \mathrm{mg} /$ day. Seven days after initiating treatment, the child developed a clinical picture consisting of headaches, vomiting, ocular pain, blurred vision, and systemic hypertension of $177 / 99 \mathrm{mmHg}$. There was no prior history of ocular disease or family history of glaucoma. Ophthalmologic examination revealed slight conjunctival hyperemia and an IOP (measured with Icare TAO1, Icare, Espoo, Finland) of $52 \mathrm{mmHg}$ on the right eye (OD) and $56 \mathrm{mmHg}$ on the left eye (OS). Pupils were symmetric and reactive to light. No papillary edema or peripapillary hemorrhages were seen in either eye. Pachymetry indicated a corneal thickness of $520 \mu \mathrm{m}$ OD and $518 \mu \mathrm{m}$ OS. An ultrasound biomicroscopy was performed to assess anterior segment morphology. No echographic abnormalities of the ciliary body were found, and the iridocorneal angle was open, measuring more than $35^{\circ}$ (Figure 1). Treatment was initiated at an emergency department with latanoprost and the fixed association of timolol and dorzolamide. A good IOP

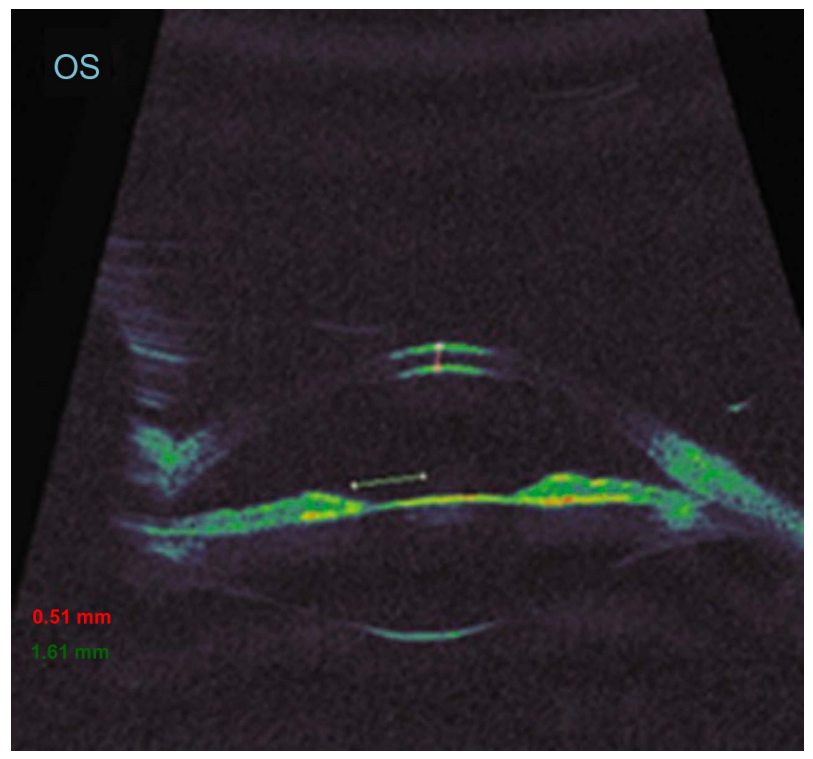

Figure I Ultrasound biomicroscopy revealed a normal corneal thickness and a wide open iridocorneal angle. response was verified. One hour later the IOP had decreased to $19 \mathrm{mmHg}$ OD and $29 \mathrm{mmHg}$ OS. Two days later the child was observed at our glaucoma department. IOP was $28 \mathrm{mmHg}$ OD and $20 \mathrm{mmHg}$ OS. In order to achieve better IOP control, brimonidine was added to the therapeutic regimen. Such a measure was successful, as 2 days later IOP was $20 \mathrm{mmHg}$ OD and $15 \mathrm{mmHg}$ OS. Brimonidine was well tolerated. One month later, prednisolone was reduced to $40 \mathrm{mg} /$ day and IOP was well controlled (14 $\mathrm{mmHg}$ in both eyes, measured with a Goldmann applanation tonometer), so we decided to eliminate brimonidine. A successful gonioscopy revealed a Shaffer grade 4 angle with no peripheral anterior synechiae or increased trabecular pigment. At the second month of follow-up, prednisolone dosage was $30 \mathrm{mg}$ /day and IOP was measured as $10 \mathrm{mmHg}$ OD and $6 \mathrm{mmHg}$ OS, so we continued to reduce antiglaucomatous medication. Due to the low IOP in OS we chose to stop the fixed association of timolol and dorzolamide. A kinetic perimetry was scheduled and no visual field defects were found in either eye (Figure 2). At the third month of follow-up, the child was medicated with $15 \mathrm{mg} /$ day of prednisolone for the nephrotic syndrome and latanoprost for IOP control, which was still maintained $(10 \mathrm{mmHg}$, both eyes (OU)), so we suspended antiglaucomatous medication. One month later we reobserved the child, having completed steroid treatment 10 days earlier and now presenting under no topical or systemic medication whatsoever. IOP was maintained at $10 \mathrm{mmHg}$ in both eyes (OU), no disc rim defects were found, and cup-to-disc ratio was $0.3 \mathrm{OU}$ (Figure $3 \mathrm{~A}$ and B). Optical coherence tomography (Spectralis, Heidelberg Engineering, Heidelberg, Germany) was scheduled to document the status of the peripapillary nerve fiber layer. No defects were found in any of the six analyzed sectors, and the global nerve fiber layer thickness was $91 \mu \mathrm{m}$ OD and $94 \mu \mathrm{m}$ OS (Figure 3C and D). Our final observation, 6 months after completing steroid treatment, revealed a normal ophthalmologic examination with an uncorrected visual acuity of 20/20 OD and 20/20 OS (cycloplegic refraction of $+1.00 \mathrm{D}$ OU) and normal IOP (12 mmHg OU).

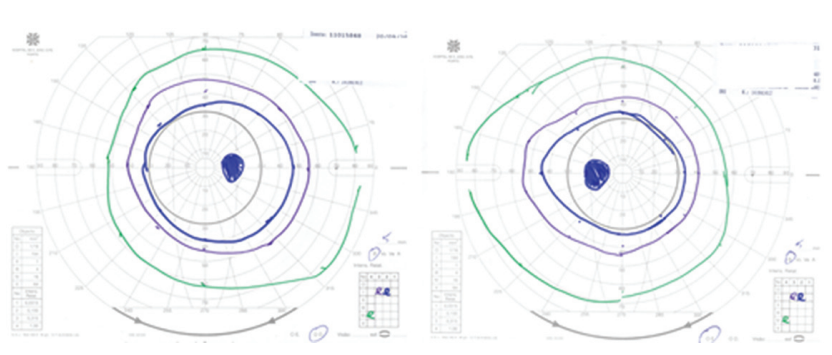

Figure 2 Kinectic perimetry at the third month of follow-up revealed normal isopter amplitude in both eyes. 


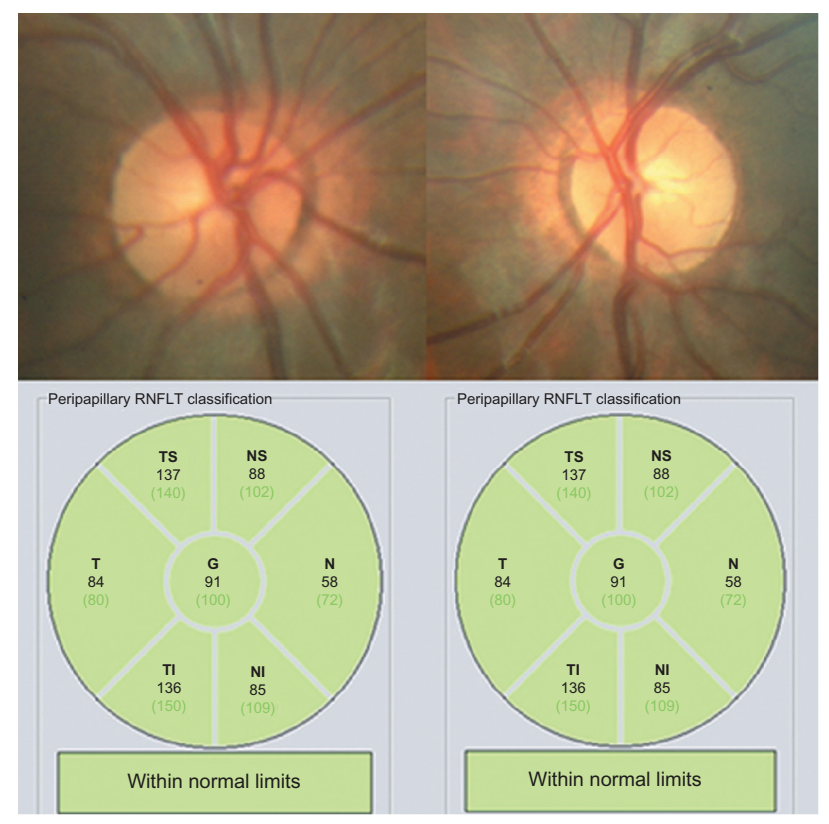

Figure 3 At the end of follow-up (4 months), a normal cup-to-disc ratio was seen in both eyes, and optical coherence tomography revealed a normal peripapillary retinal nerve fiber layer thickness.

Abbreviations: G, global; N, nasal; NI, inferonasal; NS, superonasal; TI, inferotemporal; TS, superotemporal.

\section{Discussion}

Our case illustrates a severe, dose-dependent IOP response to systemic steroid treatment, identifiable in two major observations. Firstly, a temporal relation between corticosteroid dosage and the number of antiglaucomatous agents required to control IOP was present. Secondly, an important point to consider is the very small time frame required to obtain an IOP response, which is mostly evident on the first observation when an IOP higher than $50 \mathrm{mmHg}$ was verified in both eyes precisely 7 days after initiating $60 \mathrm{mg}$ /day of prednisolone. We were fortunate that this case developed ocular complaints, allowing the detection of IOP elevation on the seventh day. Nevertheless, such a response may have started even earlier, as in most cases reported in the literature the children were asymptomatic. ${ }^{11,12}$ The findings that there was no family history of glaucoma, that ultrasound biomicroscopy revealed a normal anterior segment, and the absence of gonioscopic abnormalities exclude any previous ocular susceptibility to elevated IOP, meaning that the only identifiable cause explaining the severely elevated IOP verified in our case was the systemic treatment. Others risk factors for steroid-induced IOP response, such as connective tissue disease, type 1 diabetes, and high myopia, ${ }^{13}$ were also excluded.

It has been reported that approximately a third of the population develops steroid-induced ocular hypertension (OHT), and the majority of primary open-angle glaucoma
(POAG) patients are moderate to high steroid responders. ${ }^{14}$ In addition, steroid-responsive nonglaucomatous individuals have a higher risk of developing POAG compared with steroid nonresponders. ${ }^{15}$ Steroid-induced glaucoma shares many physiological and clinical symptoms with POAG. It is known that corticosteroids inhibit certain trabecular meshwork (TM) cellular functions, such as phagocytosis ${ }^{16,17}$ and cell migration, ${ }^{18}$ leading to increased resistance to aqueous outflow, but the pathogenic mechanism causing susceptibility to a steroid response is still unknown. ${ }^{19}$

Most recent studies investigating the mechanisms underlying steroid responsiveness have been focused on the differential expression of glucocorticoid receptor (GR) isoforms by TM cells of steroid-responsive individuals (or those with POAG) when compared with nonresponders. ${ }^{17,20}$ There are two isoforms of GR, resulting from alternative splicing of the human GR gene, NR3C1. GR $\alpha$ is the pharmacologic receptor for glucocorticoids (GCs) and is the classical active isoform, whereas GR $\beta$ functions as a dominant negative regulator of GR $\alpha$ transcriptional activity. ${ }^{21}$ It has been reported that most normal TM cells express relatively higher amounts of GR $\beta$ compared with glaucomatous TM cells, making the latter more sensitive to GCs. ${ }^{20} \mathrm{~A}$ recent study by Jain et al ${ }^{22}$ found that the presence of certain spliceosomes in TM cells regulates alternative splicing of GR, leading to an altered GR $\beta$ :GR $\alpha$ ratio and therefore modulating responsiveness to dexamethasone. They concluded that different levels or activity of these spliceosomes may account for differential GC sensitivity among the normal and glaucoma populations. It is likely that in steroid-responsive individuals, several genes have to be unregulated, leading to altered TM protein profiles, ${ }^{23}$ which are probably responsible for the exaggerated IOP response.

The fact that there was no discernible family history of glaucoma does not exclude genetic susceptibility to steroidinduced OHT for this case, for obvious reasons. The fact that POAG is characterized by insidious and slow clinical evolution means that the child's parents may not be fully aware of their relatives' ophthalmologic history. Also, both parents are still in their early forties, and to their knowledge have not recently been prescribed any form of steroid treatment. It is understandable, then, that the signs of POAG or steroidrelated OHT may not have had the time or opportunity to manifest in the child's parents.

Our case also underlines the importance of prompt antiglaucomatous treatment, as this child was able to complete the planned steroid treatment, and at the fourth month of follow-up no optic disc abnormalities were found and an 
intact nerve fiber layer was present in both eyes. Also, it is important to note that no ocular or systemic adverse reactions were found during the entire duration of antiglaucomatous treatment. Our major concern was systemic events, as blood volume in children is only a fraction of that in adults, meaning that the same dosage of ocular medication results in a higher systemic concentration in children. ${ }^{24}$ Both timolol and dorzolamide have been found to be well tolerated in children younger than 6 years. ${ }^{24,25}$ Latanoprost, although not as extensively studied in the pediatric population as the other agents, is characterized by an excellent systemic risk profile in adult patients. The most dangerous agent is brimonidine, which due to its lipophilic properties passes readily through the blood-brain barrier, potentially leading to central nervous system toxicity. We opted to include brimonidine, taking into account the acute onset and magnitude of IOP elevation associated with the fact that the fixed association of timolol and dorzolamide plus latanoprost had not been able to successfully control IOP. Also, the greatest risk for central nervous system side effects has been reported for children younger than 6 years. Additionally, in order to minimize the occurrence and severity of systemic events, we instructed the parents to perform punctal occlusion when administering the eye drops. We also alerted them to visit the emergency department immediately in the presence of any of the major signs of adverse reactions (respiratory distress, somnolence, paresthesia, dizziness) and, finally, we scheduled close follow-up examinations in order to stop brimonidine, and later the other antiglaucomatous eye drops, as soon as IOP was under control.

Finally, our report reveals the importance of routine ophthalmologic examination in all children undergoing steroid treatment. All identified cases of severe steroid responsiveness will require re-evaluations every time a new course of corticosteroid treatment is needed. Considering that most cases are asymptomatic, it seems that an appropriate surveillance plan should include an initial observation a few days after the initiation of steroid treatment and thereafter monthly observations until completing treatment. This way it will be possible to safely treat systemic conditions while preserving optic nerve function.

\section{Acknowledgments}

Meeting presentations: 54th Congress of the Portuguese Society of Ophthalmology, Vilamoura, Portugal, December 1, 2011. Tenth European Glaucoma Society Congress, Copenhagen, Denmark, June 18, 2012.

\section{Disclosure}

No financial support was received for this submission. None of the authors has a conflict of interest with the submission.

\section{References}

1. McLean J. Use of ACTH and cortisone. Trans Am Ophthalmol Soc. 1950;48:293-296.

2. Clark AF. Basic sciences in clinical glaucoma: steroids, ocular hypertension, and glaucoma. J Glaucoma. 1995;4(5):354-369.

3. Becker B. Intraocular pressure response to topical corticosteroids. Invest Ophthalmol. 1965;4:198-205.

4. Biedner B-Z, DR, Grudsky A, et al. Intraocular pressure response to corticosteroids in children. Br J Ophthalmol. 1980;64:430-431.

5. Ng JS, Fan DS, Young AL, et al. Ocular hypertensive response to topical dexamethasone in children: a dose-dependent phenomenon. Ophthalmology. 2000;107(11):2097-2100.

6. Kwok AK, LD, Ng JS, et al. Ocular-hypertensive response to topical corticosteroids in children. Ophthalmology. 1997;104:2112-2116.

7. Lam DS, Fan DS, Ng JS, Yu CB, Wong CY, Cheung AY. Ocular hypertensive and anti-inflammatory responses to different dosages of topical dexamethasone in children: a randomized trial. Clin Experiment Ophthalmol. 2005;33(3):252-258.

8. Armaly MF. Effect of corticosteroids on intraocular pressure and fluid dynamics. ii. the effect of dexamethasone in the glaucomatous eye. Arch Ophthalmol. 1963;70:492-499.

9. Cantrill HL, Palmberg PF, Zink HA, et al. Comparison of in vitro potency of corticosteroids with ability to raise intraocular pressure. $\mathrm{Am}$ J Ophthalmol. 1975;79(6):1012-1017.

10. Bernstein HN, Mills DW, Becker B. Steroid-induced elevation of intraocular pressure. Arch Ophthalmol. 1963;70:15-18.

11. Tham CC, Ng JS, Li RT, et al. Intraocular pressure profile of a child on a systemic corticosteroid. Am J Ophthalmol. 2004;137(1):198-201.

12. Lam DS, Fan DS, Ng JS, et al. Ocular hypertensive and anti-inflammatory responses to different dosages of topical dexamethasone in children: a randomized trial. Clin Experiment Ophthalmol. 2005;33(3):252-258.

13. Mandelkorn R. Drug-induced glaucoma. Clinical Pathways in Glaucoma. In: Zimmerman TJ, Kooner KS, editors. New York, NY: Thieme; 2001.

14. Armaly MF, Becker B. Intraocular pressure response to topical corticosteroids. Fed Proc. 1965;24(6):1274-1278.

15. Kitazawa Y, Horie T. The prognosis of corticosteroid-responsive individuals. Arch Ophthalmol. 1981;99(5):819-823.

16. Matsumoto Y, Johnson DH. Dexamethasone decreases phagocytosis by human trabecular meshwork cells in situ. Invest Ophthalmol Vis Sci. 1997;38(9):1902-1907.

17. Zhang X, Ognibene CM, Clark AF, Yorio T. Dexamethasone inhibition of trabecular meshwork cell phagocytosis and its modulation by glucocorticoid receptor beta. Exp Eye Res. 2007;84(2):275-284.

18. Clark AF, Wilson K, McCartney MD, et al. Glucocorticoid-induced formation of cross-linked actin networks in cultured human trabecular meshwork cells. Invest Ophthalmol Vis Sci. 1994;35(1):281-294.

19. Clark AF, Wordinger RJ. The role of steroids in outflow resistance. Exp Eye Res. 2009;88(4):752-729.

20. Zhang X, Clark AF, Yorio T. Regulation of glucocorticoid responsiveness in glaucomatous trabecular meshwork cells by glucocorticoid receptor-beta. Invest Ophthalmol Vis Sci. 2005;46(12):4607-4416.

21. Oakley RH, Sar M, Cidlowski JA. The human glucocorticoid receptor beta isoform. Expression, biochemical properties, and putative function. J Biol Chem. 1996;271(16):9550-9559.

22. Jain A, Wordinger RJ, Yorio T, Clark AF. Spliceosome protein (SRp) regulation of glucocorticoid receptor isoforms and glucocorticoid response in human trabecular meshwork cells. Invest Ophthalmol Vis Sci. 2012;53(2):857-866. 
23. Danias J, Gerometta R, Ge Y, et al. Gene expression changes in steroid-induced IOP elevation in bovine trabecular meshwork. Invest Ophthalmol Vis Sci. 2011;52(12):8636-8645.

24. Coppens G, Stalmans I, Zeyen T, Casteels I. The safety and efficacy of glaucoma medication in the pediatric population. J Pediatr Ophthalmol Strabismus. 2009;46(1):12-18.
25. Ott EZ, Mills MD, Arango S, et al. A randomized trial assessing dorzolamide in patients with glaucoma who are younger than 6 years. Arch Ophthalmol. 2005;123(9):1177-1186.

\section{Publish your work in this journal}

Clinical Ophthalmology is an international, peer-reviewed journal covering all subspecialties within ophthalmology. Key topics include: Optometry; Visual science; Pharmacology and drug therapy in eye diseases; Basic Sciences; Primary and Secondary eye care; Patien Safety and Quality of Care Improvements. This journal is indexed on

Submit your manuscript here: http://www.dovepress.com/clinical-ophthalmology-journal

\section{Dovepress}

PubMed Central and CAS, and is the official journal of The Society of Clinical Ophthalmology (SCO). The manuscript management system is completely online and includes a very quick and fair peer-review system, which is all easy to use. Visit http://www.dovepress.com/ testimonials.php to read real quotes from published authors. 